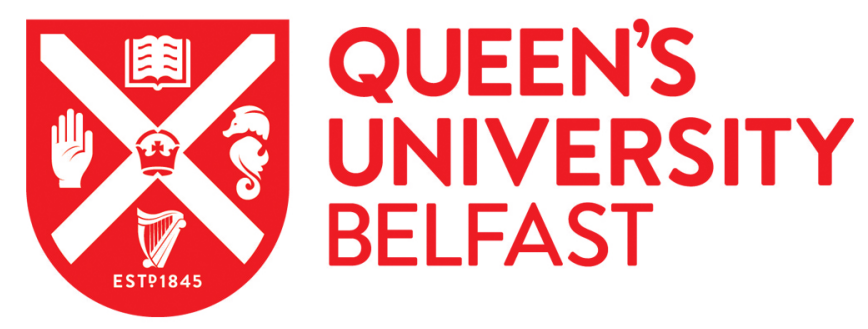

\title{
Primary Health Care Providers' Perspectives: Facilitating Older Patients' Access to Community Support Services
}

Ploeg, J., Denton, M., Hutchinson, B., McAiney, C., Moore, A., Brazil, K., Tindale, J., Wu, A., \& Lam, A. (2016). Primary Health Care Providers' Perspectives: Facilitating Older Patients' Access to Community Support Services. Canadian Journal on Aging. https://doi.org/10.1017/S0714980816000568, https://doi.org/10.1017/S0714980816000568

Published in:

Canadian Journal on Aging

Document Version:

Peer reviewed version

Queen's University Belfast - Research Portal:

Link to publication record in Queen's University Belfast Research Portal

Publisher rights

This article has been published in a revised form in Canadian Journal on Aging http://dx.doi.org/10.1017/S0714980816000568. This version is free to view and download for private research and study only. Not for re-distribution, re-sale or use in derivative works. Copyright $(9$ COPYRIGHT: (C) Canadian Association on Gerontology 2016

\section{General rights}

Copyright for the publications made accessible via the Queen's University Belfast Research Portal is retained by the author(s) and / or other copyright owners and it is a condition of accessing these publications that users recognise and abide by the legal requirements associated with these rights.

Take down policy

The Research Portal is Queen's institutional repository that provides access to Queen's research output. Every effort has been made to ensure that content in the Research Portal does not infringe any person's rights, or applicable UK laws. If you discover content in the Research Portal that you believe breaches copyright or violates any law, please contact openaccess@qub.ac.uk. 
Primary Health Care Providers' Perspectives on Facilitating Older Patients' Access to Community Support Services: A Qualitative Descriptive Study

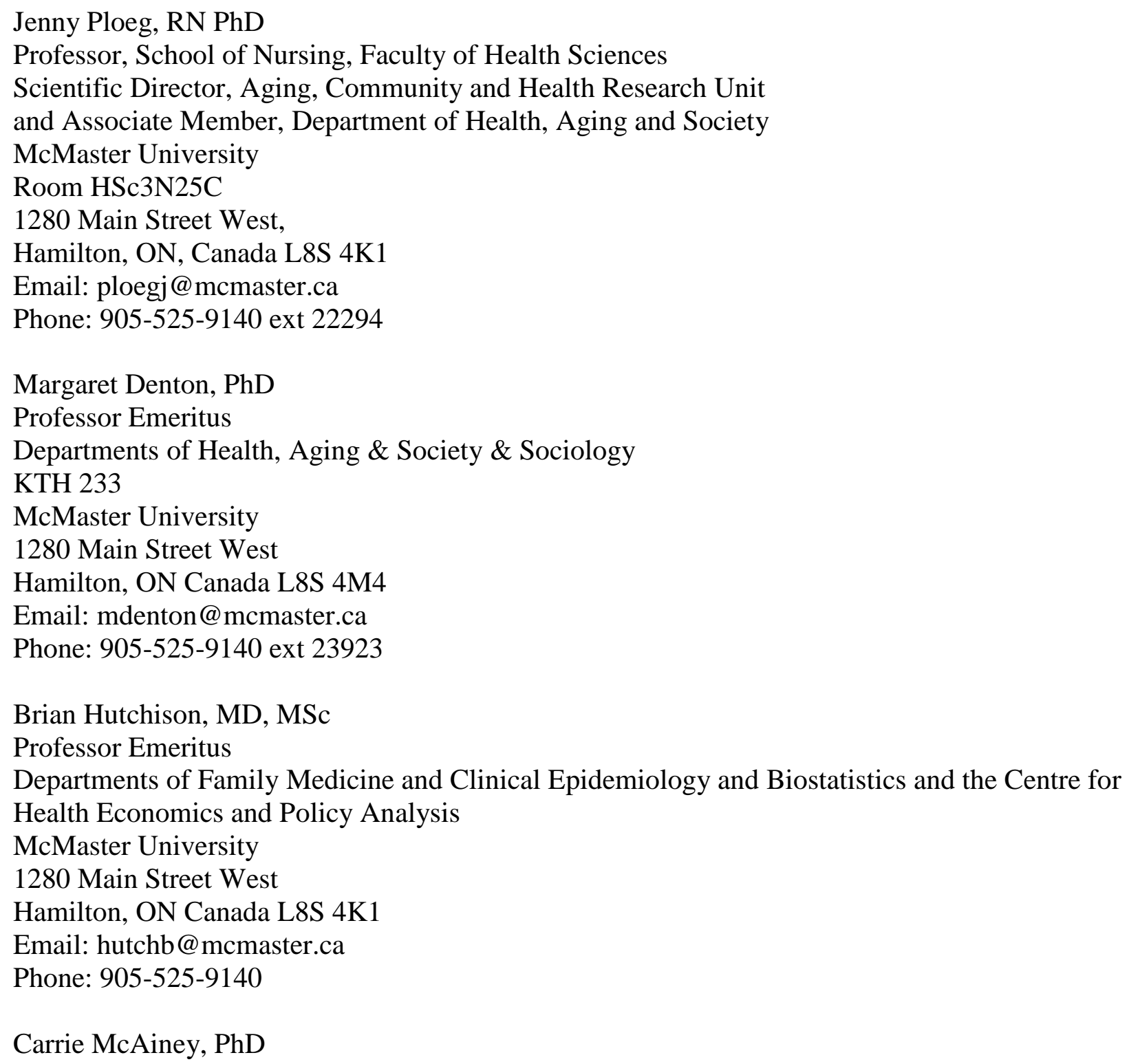


Associate Professor,

Department of Psychiatry \& Behavioural Neurosciences and

Director, Research and Evaluation, Seniors Mental Health Service

St. Joseph's Healthcare Hamilton

100 West 5th Street, Rm G102

Hamilton, ON Canada L8N 3K7

Email: mcaineyc@mcmaster.ca

Phone: 905-522-1155 ext 36722

Ainsley Moore, MD, MSc, CFPC, MSc Cand (Epi)

Associate Professor

Department of Family Medicine

McMaster University

175 Longwood Road South

Hamilton ON Canada L8P 0A1

Email: amoore@mcmaster.ca

Phone: 905-525-9140

Kevin Brazil, $\mathrm{PhD}$

Professor of Palliative Care

School of Nursing and Midwifery

Queen's University Belfast, UK

Medical Biology Centre

97 Lisburn Road

Belfast BT( 7BL

Email: k.brazil@qub.ac.uk

Phone: +44(0)28 90975782

Joseph Tindale, PhD

College Professor Emeritus

Department of Family Relations \& Applied Nutrition

University of Guelph

50 Stone Road East

Guelph, ON Canada N1G 2W1

Email: jtindale@uoguelph.ca

Phone: 519-824-4120

Amina $\mathrm{Wu}, \mathrm{BScN}$

School of Nursing, Faculty of Health Sciences

Aging, Community \& Health Research Unit

McMaster University

1280 Main Street West

Hamilton, ON Canada L8S 4K1

Email: amina.wu@gmail.com

Phone: 905-525-9140 
Annie Lam, BScN, MScN Student

Graduate Research Assistant

School of Nursing, Faculty of Health Sciences

Aging, Community \& Health Research Unit

McMaster University

1280 Main Street West

Hamilton, ON Canada L8S 4K1

Email: lama36@mcmaster.ca

Phone: 905-525-9140

Short Title: Access to Community Support Services

Keywords: community support services, primary health care, older adults, qualitative research 


\begin{abstract}
The purpose of this paper is to understand how non-physician health care professionals working in Canadian primary health care settings facilitate older persons' access to community support services (CSSs). The use of CSSs has positive impacts for clients, yet they are underused due to lack of awareness. Using a qualitative description approach, 20 health care professionals from various disciplines and primary health care models were interviewed about the processes they use to link older patients to CSSs. Participants collaborated extensively with their interprofessional colleagues within and outside their organizations to find relevant CSSs. They actively engaged patients and families in making these linkages and ensured follow-up. It was troubling to find that they relied on out-of-date resources and inefficient search strategies to find CSSs. Our findings can be used to develop resources and approaches to better support primary health care providers in linking older adults to relevant CSSs.
\end{abstract}




\section{Introduction}

Many older adults desire to remain in their own homes for as long as possible.

Governments also desire this outcome, although cost savings are the rationale behind this goal. Older adults who can maintain their health and continue to live in their own homes may use fewer more expensive health services such as emergency departments, hospital stays, and longterm care. Community support services (CSSs) play an important role in helping older adults remain in their own homes (Sinha, 2012). Many countries, including Canada, have developed a variety of CSSs to facilitate aging in place. CSSs are delivered in the home or community to help people maintain the highest possible level of functioning and quality of life. Examples of CSSs include meal services, transportation services, day programs, volunteer visiting and caregiver support services. Use of such services results in positive impacts for older adults (e.g., improved life satisfaction and mood; increased engagement in activities) and their caregivers (e.g., reduced stress, burden and depression, improved mood, life satisfaction and sense of community) (Winslow, 2003; Zarit, Gaugler \& Jarrott, 1999). Despite the need for and availability of these services, research shows that many CSSs are underutilized by older adults and caregivers due to their lack of awareness (Strain \& Blandford, 2002). Although older adults have identified both primary care physicians and their professional staff as their main sources of information about CSSs (Authors, 2008), we do not know what these professionals do to facilitate these linkages. Therefore, the purpose of this paper is to understand how non-physicain health care professionals (HCPs) (e.g., nurses, social workers, pharmacists) in primary care settings facilitate older persons' access to CSSs. This understanding is critical in developing approaches to improve HCPs ability to facilitate effective linkage of older adults to CSSs with the potential of 
improving quality of life, sustaining independence in the community, reducing inappropriate use of more costly services and delaying institutionalization.

\section{Literature Review}

Access to CSSs is challenging due to a number of factors, including the multiplicity of agencies and organizations that provide these services, the lack of a central access point, and the lack of awareness of such services (Strain \& Blandford, 2002). This literature review begins with a summary of awareness of CSSs among older adults and then moves to a discussion of awareness of CSSs among health care providers, who are identified by older adults as key sources of information about CSSs. Awareness in these studies includes awareness of the existence of the service and/or awareness of how to connect to the service. Research reflects wide variation in the proportion of older adults who were aware of various CSSs, ranging from 31\% to 78\% in some studies (Calsyn \& Winter, 1999b; Ward, Sherman \& LaGory, 1984; Wister, 1992). Literature indicates that knowledge or awareness of CSSs is associated with the actual use of these services and is thus a critical factor (Calsyn \& Roades, 1993; Calsyn, Roades \& Klinkenberg, 1998; Calsyn \& Winter, 2000). In addition, most of the available literature related to CSSs is outdated and combines CSSs with health services (Calsyn \& Roades; Calsyn et al., 1998; Chapleski, 1989; Krout, 1985; Kushman \& Freeman, 1986; Salvage, Jones, \& Vetter, 1988).

Most of the above studies of awareness of CSSs among older adults are limited by a type of response bias called "agency awareness overclaiming" or acquiescence bias ( Calsyn \& Winter, 1999a, p. 399). "Acquiescence bias is defined as the tendency to respond to questions affirmatively, regardless of content" (Calsyn \& Winter, 1999a, p. 400). Study respondents reported being aware of fictitious agencies embedded in lists of real agencies (overclaiming) and 
reported being aware of more real agencies on agency listings (acquiescence) than other respondents (Calsyn \& Winter, 1999a). Some studies have used open-ended questions in an attempt to overcome these biases (Snider, 1980a; 1980b).

Researchers have used vignette methodology as a way to prevent acquiescence bias. Hughes and Huby (2002) indicate that "vignettes consist of text, images or other forms of stimuli to which research participants are asked to respond. They can be presented to participants in a number of different forms, ranging from short written prompts to live events” (p. 382). The use of vignettes is an established research methodology used to closely approximate real-life decision-making situations through the use of hypothetical situations (Hughes \& Huby; Schoenberg \& Ravdal, 2000; Spalding \& Phillips, 2007). Research previously conducted by this team used vignettes to assess older adults’ awareness of CSSs (Authors, 2008; 2009; 2010). In telephone interviews, 1,152 older adults were read a series of four vignettes describing common situations where CSSs would be appropriate (Authors, 2008). Awareness of CSSs varied by the presented vignette, and ranged from $1 \%-41 \%$ of respondents being able to identify a CSS, with an average of $21 \%$ across vignettes. Across the four vignettes, $43 \%$ of respondents were unable to name even one CSS (Authors, 2011). Older adults were more likely to be aware of services to assist with caregiver burden, dementia services and transportation services. However, there was very little awareness of CSSs related to managing chronic conditions, safety, financial abuse, and finding leisure activities. When asked where they would get information about CSSs, the most common response was their family physician or family physician's office, with $26 \%$ of respondents noting this source of information (Authors, 2008). Other less commonly reported sources of information about CSSs included the telephone book, word of mouth, and the internet. 
Little is known, however, about how family physicians and their office staff support older adults to make connections with CSSs or their knowledge and awareness of such services. Researchers found that many physicians have inadequate knowledge of and underutilize CSSs such as adult day care, housing options and congregate meals (Barker, Mitteness \& Heller, 1991; Damron-Rodriguez et al., 1998; Henninger, Henninger, Morse \& Zwigenhaft, 1987; Yeo \& McGann, 1986). Research focused specifically on CSSs for older persons with dementia and their families suggests limited awareness and referrals by physicians to relevant CSSs (Fortinsky, 1998; Fortinsky, Leighton, \& Wasson, 1995; Yaffe, Orzeck \& Barylak, 2008). Limitations of this literature include the dated nature of most studies, the combination of both primary care and specialist physicians, and the lack of research approaches to address acquiescence bias.

The current study constitutes the second phase of a two-phase qualitative study on how primary HCPs link older adults to CSSs. The first phase of the study was a qualitative multiple case study of family physicians. In this phase, 23 family physicians from four different models of primary health care (Family Health Teams (FHTs), Community Health Centres (CHCs), Family Health Organizations (FHOs), and fee-for-service (FFS)) were asked how they facilitated the linkage of older patients to CSSs (Authors, in press). Across all models of primary health care, physicians collaborated extensively with their interprofessional team members to make these linkages, often delegating these activities to these individuals. Physicians were asked to identify the interprofessional team members they collaborated with to make linkages to CSS and these team members in turn were invited to participate in the second phase of the study, as reported here. We could find no literature describing how primary care HCPs other than physicians link older persons to CSSs. 
In summary, older adults have limited awareness of available CSSs and often turn to health care professionals in primary care settings to help them make these connections. Previous research shows that family physicians collaborate extensively with their inter-professional team members to facilitate patient linkages with CSSs. However, we know little about how nonphysician HCPs working in primary care settings link older patients to CSSs. The aim of this study is to understand how non-physician primary HCPs link older adults to CSSs. Study findings can be used to develop resources and approaches to better support primary HCPs to connect older adults with CSSs and ultimately to enhance their quality of life and improve their ability to live independently in their own communities.

\section{Methods}

\section{Study Design and Setting}

A qualitative description approach as described by Sandelowski (2000; 2010) was used. This approach is based on naturalistic inquiry, an approach that studies events and persons in their natural state. It aims to provide a comprehensive description using everyday terms of specific events experienced by individuals or groups of individuals. This approach was well suited to the purpose of developing a description of the processes used by HCPs to link older adults with CSSs.

The study was conducted in Hamilton, Ontario, Canada. Several primary healthcare (PHC) funding and delivery models co-exist in Ontario, most of which are represented in the city of Hamilton. Participants were recruited from four main PHC models: FHTs, CHCs, FHOs, and FFS practices (Hutchison, Levesque, Strumpf \& Coyle, 2011) (see Table 1). FHTs and CHCs consist of teams of interprofessional health professionals (often including but not limited to family physicians, nurse practitioners, nurses, social workers, mental health counsellors dietitians 
and pharmacists). These models facilitate interprofessional collaboration and sharing of knowledge and expertise in order to connect clients to CSSs. FHOs also provide comprehensive care to their patients, although they often have smaller interdisciplinary team compositions and may hire other professionals outside of their practice to provide services for clients. Fee-forservice practices are often composed of smaller teams and solo practices may include only a physician and nurse. All PHC models have access to home care case managers, but some FHTs have case managers specifically assigned to the team who meet regularly with team members.

[insert Table 1 here]

\section{Sampling and Recruitment}

In Phase 1, physicians ( $\mathrm{n}=23$ ) were purposively sampled from sampling frames of the family practices within each of the four primary care models. Where possible, maximum variation sampling was used to include solo, small and large group practices. The largest proportion of physicians (48\%) were from FHTs; there was a larger proportion from non-FHT models of care in Phase 1 (52\%) than in the current Phase 2 (30\%). Physicians were told that the purpose of this study was to understand how family physicians facilitate older patients' access to CSSs and to identify variations in the approach to making linkages across different PHC models. Primary care physicians (from phase 1) and colleagues (from phase 2) provided the names and contact information for potential study participants to the research coordinator who contacted them with information about the study and an invitation to participate.

Purposive sampling strategies were used in this study, including criterion sampling, maximum variation sampling and snowball sampling (Patton, 2002). Participants met the criterion of being non-physician professionals who worked in primary health care settings that included older adults as patients. Maximum variation sampling was used to recruit participants 
representing various disciplines (e.g., Registered Nurses, Mental Health Counsellors, Dietitians, Social Workers, Pharmacists and home care case managers) and different models of primary health care (FHT, FHO, CHC, FFS). Using snowball sampling, participants were asked to identify other HCPs that they would turn to for help when connecting older patients to CSSs.

\section{Data Collection}

Data were collected using semi-structured face-to-face interviews conducted at participants’ workplaces. A semi-structured interview guide was developed based on the guide used in the first phase of the study and a review of the literature. Participants were asked to describe what they do when an older patient needs access to CSSs and what processes they use to link the person to CSSs. They were asked to describe any resources they turn to for help in deciding where to refer older patients, and the kinds of resources they feel would be valuable to assist them. Participants were also asked to respond to two short vignettes related to older adults who require access to CSSs (See Table 2). Demographic characteristics were collected on each participant and included gender, years of practice, and type of profession. Interviews were conducted by the Research Coordinator between October 2009 and January 2011 and lasted an average of 30 minutes; each interview was audio-taped and transcribed verbatim. The Research Coordinator was experienced in conducting semi-structured interviews and the study leads were experienced in designing and conducting qualitative research studies.

[insert Table 2 here]

\section{Data Analysis}

Transcriptions of interviews were checked against the audio-tapes to ensure accuracy of the data. Transcripts were entered into NVivo 8 software to help with data management. The study leads and Research Coordinator jointly conducted the data analysis, and preliminary 
findings were discussed with the other investigators as the analytic process continued. Consistent with a qualitative descriptive design, qualitative content analysis strategies were used (Sandelowski, 2000; 2010), in particular conventional content analysis (Hsieh \& Shannon, 2005). This approach is appropriate when existing research in the area is limited (Hsieh \& Shannon). One of the advantages of this approach is that information is gained from participants without imposing a pre-existing theory or categories to the data. Consistent with this approach, transcriptions were repeatedly read and re-read to achieve immersion in the data. Line-by-line coding of the data was conducted to capture key concepts using both N-Vivo codes (arising from the data itself) and the interview questions. A coding scheme was developed and was applied by two team members on the first four transcripts, revised, and applied to the remaining transcripts. Data within codes were carefully reviewed and codes were then sorted into categories based on how the codes were linked or related to each other (Hsieh \& Shannon). Word tables were developed to display the processes used by each health care provider to link older patients to CSSs and these tables were analyzed for similarities and differences.

\section{Strategies to Ensure Rigor}

A number of strategies were used to ensure the quality of this study (Lincoln \& Guba, 1985). Given the variability of models of primary healthcare in Canada and variability of disciplinary team members in such models, study transferability was enhanced through the inclusion of participants from four different models of primary health care, as well as participants from multiple disciplines within these models. Dependability and credibility were addressed through the use of investigator triangulation where data and findings were reviewed and discussed by multiple research team members over the study period. These team members, representing a variety of disciplines and backgrounds (e.g., family practice, nursing, psychiatry, sociology, aging), brought unique perspectives to data interpretation that helped to ensure credibility of the data. An audit trail of all study decisions (e.g., sampling, data collection, data 
interpretation) was maintained.

\section{Ethics}

The Hamilton Integrated Research Ethics Board granted ethics approval of the study (09267). The Research Coordinator ensured informed consent, collection of signed consent forms and protection of participant confidentiality. Participation was voluntary and withdrawal from the study could occur at any time without consequence. No incentives were offered to physicians in Phase 1 or the non-physician healthcare providers in Phase 2 to participate in the study.

\section{Findings}

\section{Demographics}

A total of 20 HCPs participated in this study. Participants included social workers, mental health counsellors, nurses, pharmacists, dietitians and home care case managers (See Table 3). All but one of the participants were female. They worked in various primary health care models with most (70\%) working in FHTs. The proportion of older adults in their practices ranged from as low as $0-25 \%$ to as high as $75-100 \%$; $70 \%$ have older adults making up less than $50 \%$ of their practice. These HCPs also varied in their number of years of practice with similar proportions having 0-14, 15-24 and more than 25 years of experience.

[insert Table 3 here]

\section{Categories}

Four categories were identified reflecting the processes used by HCPs to link older patients to CSS: (a) collaborating with other interprofessional health care providers; (b) engaging patients and families in facilitating linkages to CSSs; (c) facilitating follow-up, and (d) using outof-date resources and inefficient search strategies to identify CSSs. The categories were 
represented by professionals from all disciplines and across each of the primary care models, and were reflected in responses to both the general interview questions and the vignettes. In regard to the level of comfort in linking older adults with CSSs, 30\% of the HCPs reported that they felt very comfortable, $60 \%$ felt fairly comfortable and only $10 \%$ stated that they were uncomfortable in facilitating linkages. Participants working in a team-based primary health care model explained that they felt comfortable because they were able to rely on others within the practice to help them if they needed to link older adults.

HCPs were asked during the presentation of vignettes to list specific CSSs that they would use in the vignette scenarios. They listed 18 different CSSs across the two vignettes. In response to the first vignette, $85 \%$ of participants identified the Alzheimer's Society. In response to the second vignette, $60 \%$ identified Meals on Wheels. Other frequently mentioned CSSs included friendly visiting services, seniors' home help services, and meal/grocery services. This illustrates that in addition to acknowledging a relatively high level of comfort in facilitating linkages for their patients, HCPs demonstrated familiarity with a multitude of CSSs relevant to the vignettes. In the following description of categories, participant quotes are identified by participant number, PHC model, and profession.

\section{Collaborating with other Interprofessional Health Care Providers}

The most common process described by participants to facilitate linkages of older patients to CSSs involved collaborating with other interprofessional HCPs. This collaboration involved communicating and consulting with others, both within and beyond their teams, to find resources that would best meet patient needs. HCPs recognized that different team members had diverse experiences and knowledge bases related to CSSs. Participants indicated that they most frequently consulted with nurses (Registered Nurses, Registered Practical Nurses, Nurse 
Practitioners) as many had previous community work experience and knowledge related to CSSs.

I will talk to the other nurses on the team. There's one other nurse on our team and she has a lot of experience linking with community services and using different services. She has a ton of experience within the family practice. (001 FHT Nurse)

One participant from a larger practice stated that they "have a team of seven nurses, so within seven of us everyone has a different aspect of knowledge" (011 FHO Nurse).

HCPs who worked within FHTs or other primary care models with larger interprofessional teams described consulting with a diversity of professionals who often worked in the same location:

There [are] two mental health counsellors here...Or the nurse. Our nurse here is very knowledgeable. We work in a collaborative model here so I could talk to the family doc. I could talk to the nurse, the other mental health counsellor. I mean I have the whole Family Health Team at my disposal so I know where the resources are if I feel stuck in any way. (008 FHT Mental Health Counsellor)

HCPs who worked in smaller primary care practices spoke of the limited support from other team members in making linkages to CSSs: "Other groups have more access to like a social worker...There's just the doctor, the nurse and the receptionist in our practice, so we don't have a lot of support here" (017 FFS Nurse).

Most participants explained that they consulted with home care case managers to make linkages not only to home care services, but also to CSSs: “[I] rely ninety-nine percent of the time on our home care case manager" (009 FHT Nurse). In some FHTs, specific home care case managers were assigned to the team, making collaboration easier:

I liaise very closely with the home care case manager that's connected with our family health team. So, she provides me with updates or anything that's new, and vice versa. Or I'll keep her connected... she's another good resource for me. (003 FHT Social Worker) 
HCPs explained that they involve case managers in patient situations because they are

knowledgeable about CSSs and able to provide individual home assessments, which in turn help to guide selection of CSSs to address patient needs.

We use [case managers] a lot. And they do an awful lot. They do the assessments...go to the home and check the home to see if they've got bars in the bathroom. They check the home for safety. They really do a very thorough test. (002 FHT Nurse)

Many HCPs consult with other professionals outside their practice settings to learn about different CSSs available for their patients. This was particularly important when they encountered complex or new situations that they did not have experience with.

I will call former colleagues who are still working in community programs. Some of them are in health programs. A lot of them work in day programs and are still linked with community services. So, I will contact them just on a personal level and say: 'I have this case and what do you think? And I'm thinking about directing them here. Do you think that would work?'(001 FHT Nurse)

I have a friend who's a discharge planner at the hospital. I pick her brain for a lot of scenarios that I haven't come against before. (019 CHC Case Manager).

Overall, HCPs collaborated extensively with a range of interprofessional colleagues who had more experience or knowledge about CSSs in order to facilitate linkages of their older patients to appropriate CSSs.

\section{Engaging Patients and Families in Facilitating Linkages to CSSs}

HCPs described a number of processes they used to engage patients and families to help facilitate linkages to CSSs. The term 'facilitating linkages' used in this paper includes a variety of strategies that could result in use of CSSs such as providing information to older adults and caregivers on available CSSs or contacting CSSs to obtain information about their services to share with patients and caregivers, or more actively actually making referrals. HCPs explained that they often begin by meeting with patients and families to assess the needs and wishes related 
to CSS, including their attitudes to accepting such services. They often give information about available services including eligibility and costs. Further, HCPs encourage participation of patients and families in setting priorities and making decisions related to CSSs. HCPs then determine, in consultation with patients and families, who will make the contact with the agency. This decision is made by considering both the abilities of the patient and family and a desire on the part of HCPs to encourage independence.

Participants described team work as including older adults and families: "You gotta' work together as a team with the elderly" (015 FHT Mental Health Counsellor). HCPs explained that they have "family meetings" (018 CHC Occupational Therapist) with patients and families to assess their preferences for support and determine which services would best meet their needs: We'll first talk to the senior, find out what they need, what sort of family backup they need. We have facilitated some meetings of family and senior to identify what the senior really needs help with. (011 FHO Nurse)

Generally the process is to identify areas that they're struggling with, to give them some idea what services are available, and see which ones would work for the patient - which ones they think would be acceptable. And we talk about the advantages and disadvantages of different programs and approaches. (001 FHT Nurse)

HCPs often provide patients and families with information about CSSs to help them make the needed connections. One participant described the importance of "[educating clients about] what's out there...leaving clients with a list of what programs are offered, their descriptions, and contacts" (019 CHC Case Manager). In order to do this, HCPs often directly contacted CSSs to gather information regarding the service and referral process:

I'd talk to the people at the service and see what needs to be done in terms of referral or application or, is there some kind of means test or, what's the catchment or... will this person be able to access that? I would if needed, I'd assist the family or the senior with application or whatever they need. (016 FHT Social Worker) 
Participants described involving families in making decisions about CSSs. Family members assisted with prioritizing goals for the older adult and helping to choose appropriate services that would maximise the quality of life for the older adult. HCPs will often "ask a family member to help come up with [decisions]" (003 FHT Social Worker).

HCPs described how they made decisions about actually contacting CSSs:

The idea certainly would always be to empower the clients [and their families] and encourage them to do it for him or herself. But if [they] would like help in doing it, I am happy to do it for them, to make the referral. (020 FHO Social Worker)

HCPs described "[passing] that responsibility [of contacting community agencies] onto the family to do...to get them to take ownership" (006 FHT Mental Health Counsellor). This was especially the case when a certain support or service required self-referral by the client or family member:

I would...give them some phone numbers and they may have to do some of that themselves. So, they could do the phoning, they could find out the cost and everything. So, basically what I would do for those that are self-referral I could give her some numbers to call and some agencies to call. I would probably do that rather than do it myself. (002 FHT Nurse)

Finally, HCPs recognized some of the barriers older patients and families face in obtaining or accepting CSSs such as the cost of services.

You have a population that is elderly, and doesn't have a lot of money...we have clients that they're not going to spend twenty dollars on a day program...It costs more money to get certain services. It's a barrier for our clients (018 CHC Occupational Therapist).

HCPs used this understanding of barriers to guide strategies that facilitate use of CSSs, such as slowly and consecutively introducing new services: "seniors are easily overwhelmed particularly if they've been sort of more house-bound for any length of time. By introducing too many new services all at once I find they get overwhelmed and they’ll cancel everything" (001 FHT Nurse). HCPs recognized that the patient's level of readiness, financial resources, and level of stress can 
affect the uptake and use of CSSs and talked about how they supported patients in making decisions related to CSSs.

I have to make sure that the client is in agreement. A lot of times the clients want to think about it... I'll give them a basic explanation of the program, and then I explain to them who the person is that will contact them, and at that point, I let them know that they still have the option to refuse or to accept [the service]... A lot of them will accept, but a lot of them will also say, 'No, I think I'll wait.' I've had people call me back six months later and say, 'You know, I'm ready now.' (019 CHC Case Manager)

\section{Facilitating Follow-Up}

HCPs recognized that the process of linking older patients to CSSs does not end with making the contact with the service, but extends to include a number of follow-up activities. Participants state that they "follow-up with [patients] to see if they've connected, how it's working, and what else they might need" (007 FHT Dietitian). HCPs acknowledged the challenges older persons experience in making connections with CSSs and identified the important role they could play in facilitating follow-up.

[It is helpful to have] somebody who can link people to resources and do follow-ups on calls, because you can tell seniors about services, but you have to help them link. I know that sounds very paternalistic but they often find it very difficult to make that phone call. And they often appreciate if you call and the person from that agency contacts them...Even though we think that people should be proactive, it doesn't work about fifty percent of the time. And these are not necessarily people that are not intelligent or have poor education. These are people that are struggling and feeling helpless and need someone to make an extra step to demonstrate that they're interested in helping them. (001 FHT Nurse)

HCPs facilitate follow-up by creating an environment for ongoing, open communication and the development of a helping relationship with patients and families. HCPs describe making themselves available to patients and families by providing them with the HCP's contact information and encouraging them to ask questions and contact them if they encounter issues.

And I offer again 'if you have any questions between now and the next time we meet... you can feel free to call me.'... might say 'Do you mind if I do a telephone call? Can I check in with you in such and such amount of time?'(014 FHT Mental Health Counsellor) 
HCPs ensure that family members are "kept in the loop" (013 FHT Nurse) with "what's going on just in case [they] are not aware" (008 FHT Mental Health Counsellor). These collaborative encounters facilitate the development of a comprehensive approach to addressing patient and family needs and helps to determine which CSSs are most appropriate for the older person. When HCPs noted that there were issues in connecting with a CSS, they offered to act as mediators, to "[talk] to the people at the service or if they needed information [I could help] give them information [about the client]” (016 FHT Social Worker).

\section{Using Out-of-Date Resources and Inefficient Search Strategies to Identify CSSs}

Many HCPs referred to the use of out-of-date resources and inefficient search strategies to identify appropriate CSSs for older adults. Although they use a variety of different resources including books, internet websites, pamphlets and conferences, there is no efficient and systematic way to identify appropriate CSSs for older adults. Many described using a hard copy of 'The Red Book' which was developed by a local community information service and last updated in 2007. However, participants acknowledged that "the community services little booklet [is] old" (008 FHT Mental Health Counsellor).

HCPs describe using the internet as a "good resource” (002 FHT Nurse) for finding CSSs. They do keyword searches in search engines such as Google. While they acknowledge that "the internet sometimes is the most up-to-date" (016 FHT Social Worker), they also recognize it may be an inefficient way to find CSSs. Some HCPs refer to specific internet websites and databases to help them find information on CSSs. These websites include family health team sites and the Alzheimer's Society. A few HCPs mentioned using the website version of 'the Red Book' which contains 4,000 records of community and government services for all age groups: "Information Hamilton or something. It's a website that a lot of the social workers 
use. And I use that website as well" (001 FHT Nurse). However, it is difficult to find CSSs specifically for older adults or specific care needs on the site.

HCPs also report using a variety of written resources related to CSSs. Some HCPs have created their own binder of CSSs that they use. One FHT has collated an information booklet on a broad range of community services that their employees can use.

The family health team has put together a couple of pages of information about all that the community has out there... [information on] How to Get Active - fitness clubs, mall walking, retail stores, healthy eating websites, different support groups... cooking classes... family health team kind of just collected it. (004 FHT Pharmacist)

Some HCPs prefer having their own individualized catalogue of resources because they are smaller, easier to navigate, and provide a way for participants to "look up [resources] real quick" (015 FHT Mental Health Counsellor).

Finally, HCPs report using information from brochures available in their workplaces or at conferences and workshops to link older adults with CSSs.

"I have been to some of the workshops that are put on, have a lot of resources there. So, I take advantage of all that...display booth presentations...and make sure I grab all ... the flyers and the brochures. And I talk to people at the booths. So, that's really important." (003 FHT Social Worker)

Although HCPs describe using a variety of resources and methods when looking for CSSs for their older clients, there is no central point of access that provides a comprehensive, up-to-date list of current and easily searchable CSSs.

\section{Recommendations}

During the interviews, participants were asked to make suggestions for resources, services or supports that would help them to facilitate linkages between older adults and CSSs. Their two recommendations were: (a) the development of a central, easily searchable source of up-to-date information on CSSs; and (b) the provision of more information on available CSSs. 
Participants described the need for a centralized location where all information about CSSs could be readily accessed: "if there were a one-stop place to go and look for what is available in our area...[including] eligibility criteria, cost and description of the program...that would be helpful [because] trying to keep myself stocked and aware of those things, it can be a barrier, time-wise” (007 FHT Dietitian). Some participants indicated their preference for a hardcopy resource while others preferred an internet resource. HCPs stated that they require “quick and easy brochures” (001 FHT Nurse) or "pamphlets to hand somebody” (006 FHT Mental Health Counsellor). Participants emphasized that these resources had to be kept up-todate.

Some HCPs preferred internet-based central repositories of CSSs: "If we had a place to look for links for services for senior citizens on the internet, that would be as good as a booklet for referrals" (002 FHT Nurse). Participants further discussed having a search engine where, with specific patient details, they could match a CSS with an older adult: "[I would like it if] there was an internet-based repository of all of the services...you could put [what your patient needs] into the search engine and have some things come back” (005 FHT Pharmacist).

Second, HCPs identified the need for more information on available CSSs as they felt they lacked awareness of these services. Participants wanted "to hear more from the support programs out there...[I] want to know more about them... about what's new... has [their] referral form changed and has [their] admission criteria changed" (006 FHT Mental Health Counsellor). They also felt that it would be helpful to have educational sessions or workshops about available CSSs. In particular, they felt it "would be really helpful in terms of staying up to date if Hamilton could have a community services networking day where you could just connect with people in 
different organizations. Just to make sure that you're up to date on what services they offer" (001 FHT Nurse).

\section{Discussion}

Study findings shed new light on how health care providers in primary care settings facilitate linkages to CSSs for older patients. First, HCPs reported that they collaborated extensively with other professionals both within and beyond their team in making these linkages. Participants described consulting and communicating with other disciplines to find services that were relevant to the needs of patients. Study findings paint a picture of HCPs who are doing a fairly good job of making linkages with CSSs and using available team resources to make these linkages. This is somewhat surprising, although encouraging, given the literature review that indicates there are important gaps in awareness of CSSs and linkages with CSSs for patients and families. It is possible that professionals who work in larger team models of primary health care, as the majority of these participants do, have a larger pool of experienced and connected colleagues to help them make appropriate connections with CSSs.

Given that many older adults seen in primary care settings have multiple chronic conditions and complex health and social needs (Fortin, Bravo, Hudon, Vanasse \& Lapointe, 2005), HCPs must work together to provide care that addresses these complex issues. An integrated team model promotes interprofessional collaboration, which helps to improve the health and functional abilities of older adults (Trivedi et al., 2013). This in turn helps to reduce caregiver burden and promotes client satisfaction and quality of care (Trivedi et al., 2013). Thus, primary health care models that have interprofessional teams may have greater potential to facilitate appropriate linkages to CSSs for older adults. 
Second, HCPs describe engaging patients and families in facilitating linkages to CSSs. This interaction was important to determine the needs of the older adult and their family members, including acceptability of CSSs. HCPs encouraged the participation of patients and families in the process of connecting with CSSs and fostered shared decision-making. Previous research confirms that patients in primary care settings express strong desires for a patientcentred approach that includes communication and partnership (Little et al., 2001). HCPs encouraged participation and collaboration by holding family meetings and involving family members in the decision-making process. Not only did this reduce the burden on family members, but it also provided HCPs an opportunity to better understand the needs of the older patient. This was especially important when HCPs encountered vulnerable older adults who were unable to articulate their needs.

Another important study finding is that HCPs provide follow-up in the process of linking older adults to CSSs. This follow-up may be particularly important where clients and families are vulnerable due to cognitive or mental health issues and language barriers. For example, previous literature indicates that caregivers of persons with dementia are often reluctant to use CSSs such as adult day programs and home supports and yet timely acceptance of such services may improve their ability to care for their loved one at home (Gaugler, Kane, Kane \& Newcomer, 2005). In one study, having health professionals make the linkages with the Alzheimer Society on behalf of caregivers of persons with dementia resulted in more timely use of this service (McAiney, Hillier, Stolee, Harvey \& Michael, 2012). Thus, follow-up by HCPs related to acceptance and use of CSSs may be an important strategy to improve uptake of such services. Most of the HCPs interviewed (75\%) in the current study indicated this as a common practice, and this was somewhat more common among HCPs in larger team practices such as FHTs (79\%) 
compared to those in other models of primary care (67\%). This category was not identified in Phase 1 interviews with family physicians.

Finally, study findings highlighted that HCPs often rely on out-of-date materials and inefficient search strategies to find information on available CSSs. Participants described using a wide variety of resources such as books, brochures, other written materials, as well as the internet as sources. Participants frequently described using a number of internet search engines to enter search terms to find nearby CSSs but this was often a time consuming and non-productive approach. Thus, it is challenging for HCPs in primary care settings to effectively and efficiently identify CSSs and facilitate linkages for older patients with these services. This category is consistent with our phase one research with family physicians (Authors, in press).

\section{Implications}

Our study findings have a number of practice implications. First, it is vital that primary care settings create an environment that facilitates interprofessional collaboration. Research indicates that family health teams are undertaking a range of interprofessional education and practice initiatives to support interprofessional collaboration (Goldman, Meuser, Rogers, Lawrie, \& Reeves, 2010). These initiatives may have an impact on processes to link older adults to CSSs but further research is needed in this area. Within Canada, the development of primary care reform initiatives has sparked the incorporation of team-based care into many provincial and territorial systems of care (Aggarwal \& Hutchison, 2012).

Some FHTs have incorporated the role of community navigators within the interprofessional team. Traditionally, navigators worked within communities of underserved clients facing various health disparities related to the different social determinants of health (Dohan \& Schrag, 2005; Freeman, 2006; Natale-Pereira et al., 2011). Although most of the 
research on patient navigators is based in cancer care, recent models of navigation have expanded to primary care and target older adults with multiple chronic conditions (Boyd et al., 2007; Boyd et al., 2009). In the Guided Care model, for example, a nurse in the primary care office works with physicians and other health care professionals to coordinate care of multimorbid older adults; as one aspect of their role, these nurses take on navigation responsibilities in facilitating access to community resources including CSSs (Boyd et al., 2007; Giddens, Tanner, Frey, Reider \& Boult, 2009). Further research is needed to explore the impact of such roles in primary care on the use of CSSs, patient and family outcomes, and costeffectiveness (Ferrante, Cohen \& Crosson, 2010).

Many older adults and their families rely on their primary health care providers for information about CSSs (Felix \& Eudy, 2010). These providers are uniquely positioned to have an impact on this aspect of the patient's care because of their knowledge of the patient and their role in providing ongoing patient care. However, the barriers they face in enacting that role, as described in this study, must be addressed. While nurses are often the most common professional group working in primary care teams, it is vital that all team members (e.g., social workers, mental health counsellors) who interact with patients and families are familiar with CSSs and have the resources needed to make these links.

Finally, consistent with recent recommendations in a number of government reports, study findings point to the need for improved information about CSSs for patients, families, health care providers and the general public (Health Canada, 2015; Sinha, 2012). Many participants noted that they consulted with home care case managers to obtain information about CSSs. According to the Canadian Home Care Association (2006), formalized and structured partnerships between home care and primary care can result in better understanding of available 
community resources and more timely introduction of services. Electronic systems that provide easy-to-search, comprehensive and up-to-date information on available CSSs should be developed and evaluated. Some recent innovations hold promise for increasing awareness of CSSs. For example, in Canada, $60 \%$ of Canadians now have access to a telephone/internet information service (www.211canada.ca) that provides information not only about CSSs but a host of other community services. In the European Union, EU-GENIE (European Generating Engagement in Networks Involvement, 2014) is an on-line service that creates maps of community support services based on an individual's self-identified needs and interests. It is vital, however, that such listings of resources are updated on a regular basis. Future initiatives should focus on developing, expanding and evaluating similar technological, online databases that provide comprehensive up-to-date information about CSSs. Our study findings revealed that HCPs are using a number of creative and team-oriented strategies to make linkages with CSSs. While centralized data sources may be important additions to the repertoire of supports available to help HCPs, their use of personal contacts and local knowledge are also recognized as valuable resources.

\section{Strengths and Limitations}

While this study had representation of a variety of interprofessional health care providers from four different primary health care models, and yielded a number of rich insights, it was conducted in only one geographic area. The diversity in primary health care models in Hamilton, Ontario may not be reflective of all models of primary health care in other settings and provinces within Canada. Thus, care is needed in applying findings to primary care practices more broadly. Study results may over-represent larger, interprofessional team models of primary health care since $70 \%$ of participants came from FHTs, while the remaining 30\% came from the three other 
healthcare models. The use of vignettes is a strength in this study as it provides a hypothetical context that replicates real-life decision-making situations, providing an understanding of what HCPs would do in such situations. While we did obtain some rich data in response to the vignettes, it is possible that longer versions of the vignettes may have generated more in-depth discussions.

\section{Conclusion}

Health care providers in primary care settings play key roles in helping older patients and their families link with CSSs that foster independent living and quality of life. Study findings reinforce the value of interprofessional collaboration in primary care settings. The study provides insight into the strategies used by HCPs to link older persons to CSSs and recommendations to improve their ability to make these linkages. This understanding can be used to develop resources and approaches to better support primary care health care providers in helping older adults use CSSs that support them to age in place. 


\section{References}

Aggarwal, M., \& Hutchison, B. (2012). Toward a primary care strategy for Canada. Ottawa (ON): Canadian Foundation for Healthcare Improvement. Available from www.cfhifcass.ca/Libraries/Reports/Primary-Care-Strategy-EN.sflb.ashx

Authors. (2008). Where would you turn for help? Older adults' awareness of community support services. Canadian Journal on Aging, 27, 359-370.

Authors. (2009). Older adults' awareness of community health and support services for dementia care. Canadian Journal on Aging, 28, 359-370.

Authors. (2010). Would older adults turn to community support services for help to maintain their independence? Journal of Applied Gerontology, 29, 554-578.

Authors. (2011). Social determinants of older adults' awareness of community support services in Hamilton, Ontario. Health \& Social Care in the Community, 19(6), 661-672. doi: 10.1111/j.1365-2524.2011.01013.x

Authors. (In press). Family physicians' perspectives on facilitating older patients' access to community support services: Qualitative case study. Canadian Family Physician.

Barker, J. C.., Mitteness, L. S., \& Heller, K. S. (1991). Physicians' knowledge of adult day health care for the elderly. Gerontology \& Geriatrics Education, 12, 1-15.

Boyd, C. M., Boult, C., Shadmi, E., Leff, B., Brager, R., Dunbar, L., Wolff, J. L., \& Wegener, S. (2007). Guided Care for multimorbid older adults. The Gerontologist, 47, 697-704.

Boyd, C. M., Reider, L., Frey, K., Scharfstein, D., Leff, B., Wolff, J., Groves, C., Karm, L., Wegener, S., Marsteller, J., \& Boult, C. (2009). The effects of Guided Care on the perceived quality of health care for multi-morbid older persons: 18-month outcomes from a cluster-randomized controlled trial. Journal of General Internal Medicine, 25, 235-242. 
Calsyn, R.J., \& Roades, L. A. (1993). Predicting perceived service need, service awareness, and service utilization. Journal of Gerontological Social Work, 21, 59-76.

Calsyn, R. J., Roades, L.A., \& Klinkenberg, W.D. (1998). Using theory to design needs assessment studies of the elderly. Evaluation and Programming Planning, 21, 277-86.

Calsyn, R., \& Winter J. (1999a). Understanding and controlling response bias in needs assessment studies. Evaluation Review,23, 399-417.

Calsyn, R. J, \& Winter, J. P. (1999b). Predicting specific service awareness dimensions. Research On Aging, 21, 762-780.

Calsyn, R. J., \& Winter, J. P. (2000). Predicting different types of service use by the elderly: The strength of the behavioral model and the value of interaction terms. Journal of Applied Gerontology, 19, 284-303.

Canadian Home Care Association. (2006). Partnership in practice: Two key strategies involving home care yield high impact benefits for primary health care in Canada. National Home Care and Primary Health Care Partnership Project. Retrieved from http://www.cdnhomecare.ca/media.php?mid=1645.

Chapleski, E.E. (1989). Determinants of knowledge of services to the elderly: Are strong ties enabling or inhibiting? Gerontologist, 29, 539-45.

Damron-Rodriguez, J., Frank, J., Heck, E., Liu, D., Sragow, S., Cruise, P., Osterwell, D. (1998). Physician knowledge of community-based care: What's the score? Annals of Long Term Care, 6, 112-121.

Dohan, D., \& Schrag, D. (2005). Using navigators to improve care of underserved patients: current practices and approaches. Cancer, 104(4), 848-855. 
EUGENIE: The EU-WISE intervention. (2014). Retrieved from: http://eu-wise.com/wpcontent/uploads/2014/02/EU-WISE_EUGENIE_Flyer_Final.pdf

Felix, H. C., \& Eudy, R. L. (2010). Sources of information for home and community-based services. Journal of Social Service Research, 36, 1-11.

Ferrante, J.M., Cohen, D.J., Crosson, J.C. (2010). Translating the patient navigator approach to meet the needs of primary care. Journal of the American Board of Family Medicine, 23(6):, 736-744.

Fortin, M., Bravo, G., Hudon, C., Vanasse, A., \& Lapointe, L. (2005). Prevalence of multimorbidity among adults seen in family practice. Annals of Family Medicine, 3(3), 223-228.

Fortinsky, R. H. (1998). How linked are physicians to community support services for their patients with dementia? Journal of Applied Gerontology, 17, 480-498.

Fortinsky, R. H., Leighton, A., \& Wasson, J. H. (1995). Primary care physicians' diagnostic, management and referral practices for older persons and families affected by dementia. Research on Aging, 17, 124-148.

Freeman, H.P. (2006). Patient navigation: A community based strategy to reduce cancer disparities. Journal of Urban Health, 83(2), 139-141.

Gaugler, J. E., Kane, R. L., Kane, R. A., \& Newcomer, R. (2005). Early community-based service utilization and its effects on institutionalization in dementia caregiving. Gerontologist, 45, 177-185.

Giddens, J.F., Tanner, E., Frey, K., Reider, L., \& Boult, C. (2009). Expanding the gerontological nursing role in Guided Care. Geriatric Nursing, 30, 358-364. 
Goldman, J., Meuser, J., Rogers, J., Lawrie, L., \& Reeves, S. (2010). Interprofessional collaboration in family health teams. Canadian Family Physician, 56, 368-374.

Health Canada. (2015). Unleashing innovation: Excellent healthcare for Canada. Report of the Advisory Panel on Healthcare Innovation. Ottawa: Author. Retrieved from: http://www.healthycanadians.gc.ca/publications/health-system-systeme-sante/reporthealthcare-innovation-rapport-soins/alt/report-healthcare-innovation-rapport-soins-eng.pdf Henninger, J. L., Henninger, W. B., Morse, C. K., \& Zweigenhaft, R. L. (1987). Physicians' awareness of services for the elderly. Gerontology \& Geriatrics Education, 7, 21-28.

Hsieh, H. F., \& Shannon, S. E. (2005). Three approaches to qualitative content analysis. Qualitative Health Research, 15, 1277-1288.

Hughes, R., \& Huby, M. (2002). The application of vignettes in social and nursing research. Journal of Advanced Nursing, 37, 382-386.

Hutchison, B., Levesque, J., Strumpf, E., \& Coyle, N. (2011). Primary health care in Canada: Systems in motion. Millbank Quarterly, 89, 256-288.

Krout, J. A. (1985). Service awareness among the elderly. Journal of Gerontological Social Work, 9, 7-19.

Kushman, J. E., \& Freeman, B, K. (1986). Service consciousness and service knowledge among older Americans. International Journal of Aging and Human Development, 23, 217-37.

Lincoln, Y. S., \& Guba, E. G. (1985). Naturalistic Inquiry. Newbury Park, CA: Sage.

Little, P., Everitt, H., Williamson, I., Warner, G., Moore, M., Gould, C., Ferrier, K., \& Payne, S. (2001). Preferences of patients for patient centred approach to consultation in primary care: Observational study. British Medical Journal, 322, 1-7.

McAiney, C.A., Hillier, L., Stolee, P., Harvey, D., \& Michael, J. (2012). 'Throwing a lifeline': 
The role of First Link in enhancing support for individuals with dementia and their caregivers. Neurodegenerative Disease Management, 2, 623-638. Natale-Pereira, A., Enard, K.R., Nevarez, L., \& Jones, L.A. (2011). The role of patient navigators in eliminating health disparities. Cancer, 117(supp. 15), 3543-3552.

Patton, M. Q. (2002). Qualitative research \& evaluation methods. (3 ${ }^{\text {rd }}$ ed). Thousand Oaks, CA: Sage.

Salvage, A. V., Jones, D. A., \& Vetter, N. J. (1988). Awareness of and satisfaction with community services in a random sample of over 75.Health Trends, 20, 88-92.

Sandelowski, M. (2000). Whatever happened to qualitative description? Research in Nursing \& Health, 23, 334-340.

Sandelowski, M. (2010). What's in a name? Qualitative description revisited. Research in Nursing \& Health, 33, 77-84.

Schoenberg, N. E., \& Ravdal, H. (2000). Using vignettes in awareness and attitudinal research. International Journal of Social Research Methodology, 3, 63-74.

Sinha, S. K. (2012). Living longer, living well. Report submitted to the Minister of Health and Long-term Care and the Minister Responsible for Seniors on recommendations to inform a seniors strategy for Ontario. Retrieved from: http://www.health.gov.on.ca/en/common/ministry/publications/reports/seniors_strategy/d ocs/seniors_strategy_report.pdf

Snider, E. L. (1980a), Awareness and use of health services by the elderly. Medical Care, 18, 1177-1182.

Snider, E. L. (1980b). Factors influencing health service knowledge among the elderly. Journal of Health and Social Behaviour, 21, 371-377. 
Spalding, N. J., \& Phillips, T. (2007). Exploring the use of vignettes: From validity to trustworthiness. Qualitative Health Research, 17, 954-962.

Strain, L. A., \& Blandford, A. A. (2002). Community-based services for the taking but few takers: Reasons for non-use. Journal of Applied Gerontology, 21, 220-235

Trivedi, D., Goodman, C., Gage, H., Baron, N., Schiebl, F., Iliffe, S., ...Drennan, V. (2013). The effectiveness of inter-professional working for older people living in the community: A systematic review. Health and Social Care in the Community, 21, 113-128.

Ward, R. A., Sherman, S. R., \& LaGory, M. (1984). Informal networks and knowledge of services for older persons. Journal of Gerontology, 39, 216-223.

Winslow, B.W. (2003). Family caregivers' experiences with community services: A qualitative analysis. Public Health Nursing, 20, 341-348.

Wister, A. V. (1992). Residential attitudes and knowledge, use, and future use of home support agencies. Journal of Applied Gerontology, 11, 84-100.

Yaffe, M. J., Orzeck, P., \& Barylak, L. (2008). Family physicians' perspectives on care of dementia patients and family caregivers. Canadian Family Physician, 54, 1008-1015.

Yeo, G., \& McGann, L. (1986). Utilization by family physicians of support services for elderly patients. The Journal of Family Practice, 22, 431-434.

Zarit, S.H., Gaugler, J.E., \& Jarrott, S.E. (1999). Useful services for families: Research findings and directions. International Journal of Geriatric Psychiatry, 14, 165-181.

Table 1. Description of Models of Primary Care

\begin{tabular}{|l|l|}
\hline \multicolumn{1}{|c|}{ PHC Model } & \multicolumn{1}{c|}{ Description } \\
\hline $\begin{array}{l}\text { Community Health } \\
\text { Centres }\end{array}$ & $\begin{array}{l}\text { CHCs provide comprehensive care through interprofessional teams. } \\
\text { CHCs differ from FHTs in their emphasis on community development } \\
\text { and the social determinants of health. CHCs have community governing } \\
\text { boards. Physicians in CHCs are paid a salary. }\end{array}$ \\
\hline
\end{tabular}




\begin{tabular}{|l|l|}
\hline Family Health & $\begin{array}{l}\text { FHOs also provide comprehensive care to their patients. Some FHOs } \\
\text { have access to additional funds which enable them to hire other health } \\
\text { professionals to provide special programs such as mental health, } \\
\text { nutrition and foot care. FHO physicians are paid using a blended } \\
\text { capitation model that includes a variety of incentive payments. }\end{array}$ \\
\hline Family Health Teams & $\begin{array}{l}\text { FHTs consist of interprofessional teams of health professionals (e.g., } \\
\text { family physicians, nurse practitioners, nurses, counselors, dietitians, } \\
\text { pharmacists) who provide comprehensive care to patients with a focus } \\
\text { on chronic disease management and disease prevention. Most FHTs are } \\
\text { physician-governed. FHT physicians are paid using a blended } \\
\text { capitation model that includes a variety of incentive payments. Some }\end{array}$ \\
$\begin{array}{l}\text { FHTs are academic FHTs and also committed to training health } \\
\text { professionals. }\end{array}$ \\
\hline $\begin{array}{l}\text { Fee-for-service } \\
\text { Practices }\end{array}$ & $\begin{array}{l}\text { Fee-for-service physicians are paid for services rendered and rarely } \\
\text { employ health professionals other than nurses. }\end{array}$ \\
\hline
\end{tabular}


Table 2: Interview Guide

\section{Interview and Vignette Questions}

\section{A. General Interview Questions}

1. What do you do when an older patient needs community support services?

2. What process do you use to link older adults to community support services?

3. Are there any resources, services or individuals that you would turn to in helping link older adults to community support services?

4. How comfortable are you with your ability to link older adults to community support services?

5. What kind of resources, services or supports would help you to link older adults to community support services?

6. Is there anything else you would like to share about your experience in making linkages to community support services?

B. Vignettes

Vignette 1: Your patient, Mrs. Brown is the main caregiver for her parent who has Alzheimer's disease. She has discovered that her mother has been taking more pills than she should. What would do if Mrs. Brown came to you with that situation?

Vignette 2: Your patient Mrs. Jones comes to you and says that due to her poor health she's no longer able to do her shopping, house work or yard work. Her family members are busy and she doesn't want to bother them. What would you do if Mrs. Jones came to you with that situation?

\section{Interview Questions Related to Vignettes}

1. Is there a community support service that you can think of that could provide help to Mrs. Brown/Jones in that situation?

2. Is there anyone in your practice that you would turn to for help to link Mrs. Brown/Jones to community support services?

3. Are there any resources or services that you would turn to for help to decide where to refer Mrs. Brown/Jones?

4. How comfortable are you with your ability to link older persons in the situation of Mrs. Brown/Jones to community support services?

5. What kinds of resources, services or supports do you feel you need to help you link older persons such as Mrs. Brown/Jones to appropriate community support services? 
Table 3. Characteristics of Health Care Providers $(n=20)$

\begin{tabular}{|l|l|}
\hline Characteristic & Number (\%) \\
\hline Profession: & $5(25)$ \\
Nurse Practitioner/Registered Nurse/Registered Practical Nurse & $4(20)$ \\
Mental Health Counselor & $4(20)$ \\
Social Worker & $2(10)$ \\
Case Manager & $2(10)$ \\
OT & $2(10)$ \\
Pharmacist & $1(5)$ \\
Dietitian & \\
\hline Gender: & $19(95)$ \\
Female & $1(5)$ \\
Male & \\
\hline Primary Health Care Model: & $14(70)$ \\
Family Health Team (FHT) & $3(15)$ \\
Non Family Health Team, Family Health Organization (FHO) & $2(10)$ \\
Community Health Centre (CHC) & $1(5)$ \\
Fee For Service (FFS) & \\
& \\
\hline Proportion of Older Adults in Practice: & $8(40)$ \\
0-25\% & $6(30)$ \\
$26-50 \%$ & $1(5)$ \\
$51-75 \%$ & $5(25)$ \\
$76-100 \%$ & \\
\hline Years of Practice: & $6(30)$ \\
$0-14$ & $6(30)$ \\
$15-24$ & $8(40)$ \\
$25+$ & \\
\hline
\end{tabular}

